\title{
Vagal Nerve Stimulation Reverses Aberrant Dopamine System Function in the Methylazoxymethanol Acetate Rodent Model of Schizophrenia
}

\author{
Stephanie M. Perez, ${ }^{1}$ Flavia R. Carreno, ${ }^{1}$ Alan Frazer, ${ }^{1,2}$ and Daniel J. Lodge ${ }^{1}$ \\ ${ }^{1}$ Department of Pharmacology and Center for Biomedical Neuroscience, University of Texas Health Science Center at San Antonio, San Antonio, Texas \\ 78229, and ${ }^{2}$ South Texas Veterans Health Care System, Audie L. Murphy Division, San Antonio, Texas 78229
}

\begin{abstract}
Vagal nerve stimulation (VNS) is an alternative therapy for epilepsy and treatment refractory depression. Here we examine VNS as a potential therapy for the treatment of schizophrenia in the methylozoxymethanol acetate (MAM) rodent model of the disease. We have previously demonstrated that hyperactivity within ventral regions of the hippocampus (vHipp) drives the dopamine system dysregulation in this model. Moreover, by targeting the vHipp directly, we can reverse aberrant dopamine system function and associated behaviors in the MAM model. Although the central effects of VNS have not been completely delineated, positron emission topographic measurements of cerebral blood flow in humans have consistently reported that VNS stimulation induces bilateral decreases in hippocampal activity. Based on our previous observations, we performed in vivo extracellular electrophysiological recordings in MAM- and saline-treated rats to evaluate the effect of chronic (2 week) VNS treatment on the activity of putative vHipp pyramidal neurons, as well as downstream dopamine neuron activity in the ventral tegmental area. Here we demonstrate that chronic VNS was able to reverse both vHipp hyperactivity and aberrant mesolimbic dopamine neuron function in the MAM model of schizophrenia. Additionally, VNS reversed a behavioral correlate of the positive symptoms of schizophrenia. Because current therapies for schizophrenia are far from adequate, with a large number of patients discontinuing treatment due to low efficacy or intolerable side effects, it is important to explore alternative nonpharmacological treatments. These data provide the first preclinical evidence that VNS may be a possible alternative therapeutic approach for the treatment of schizophrenia.
\end{abstract}

Key words: dopamine; hippocampus; schizophrenia; vagal nerve stimulation

\section{Introduction}

Approximately $1 \%$ of the U.S. population suffers from schizophrenia, a debilitating psychiatric condition (Bhugra, 2005; Saha et al., 2005). The dopamine hypothesis of schizophrenia states that enhanced dopamine signaling exists in patients and contributes to the positive symptoms of the disease (Laruelle and AbiDargham, 1999; Abi-Dargham, 2004). It is thought that aberrant mesolimbic dopamine signaling is secondary to the pathology present within hippocampal subfields. Indeed, preclinical data from studies in the methylazoxymethanol acetate (MAM) rodent model of schizophrenia (for review, see Lodge and Grace, 2009)

\footnotetext{
Received Feb. 11, 2014; revised April 23, 2014; accepted May 28, 2014.

Author contributions: S.M.P., F.R.C., A.F., and D.J.L. designed research; S.M.P. and F.R.C. performed research; S.M.P. and D.J.L. analyzed data; S.M.P., F.R.C., A.F., and D.J.L. wrote the paper.

This work was supported by NIH Grants R01 MH082933 (A.F.), R01 MH090067 (D.J.L.), and F31 MH098564 (S.M.P.).

S.M.P. and F.R.C. declare no competing financial interests. A.F. has served on advisory boards for Lundbeck, Takeda Pharmaceuticals International, and Eli Lilly; and as a consultant for Dey Pharmaceuticals. Previously, A.F. had received financial compensation as a consultant for Cyberonics and had also obtained grant support from them for a preclinical study. D.J.L. reports receiving consulting fees from Dey Pharmaceuticals.

Correspondence should be addressed to Dr Daniel J. Lodge, University of Texas Health Science Center at San Antonio, Department of Pharmacology, 7703 Floyd Curl Drive, MC 7764, San Antonio, TX 78229. E-mail: LodgeD@uthscsa.edu.

DOI:10.1523/JNEUROSCI.0588-14.2014

Copyright $\odot 2014$ the authors $\quad 0270-6474 / 14 / 349261-07 \$ 15.00 / 0$
}

provide evidence that hyperactivity within the ventral hippocampus (vHipp) drives aberrant mesolimbic dopamine signaling, as well as, hyper-responsivity to psychomotor stimulants (Lodge and Grace, 2007, 2011). This hypothesis is consistent with imaging studies in individuals with schizophrenia where hippocampal hyperactivity is observed at rest (Heckers et al., 1998; Medoff et al., 2001; Tamminga et al., 2010) and can predict symptoms of psychosis (Schobel et al., 2009b). Thus, the hippocampus may be a primary site of pathology that underlies the dopamine dysregulation in schizophrenia.

Novel therapeutic approaches for schizophrenia are essential given that current pharmacotherapies are far from adequate. One approach may be to target the hippocampus and restore downstream alterations in dopamine system function (Lodge and Grace, 2011). We have reported previously that directly targeting the vHipp with deep brain stimulation (DBS) reduces hippocampal hyperactivity, restores mesolimbic dopamine system function, and reverses behaviors associated with positive and cognitive deficits (Perez et al., 2013). Although these preclinical data are promising, DBS remains an invasive and controversial treatment. Here we report on the utility of vagal nerve stimulation (VNS) as a less invasive therapy for the treatment of schizophrenia.

Approved by the U.S. Food and Drug Administration for treatment-resistant epilepsy and depression, VNS is effective at 
reducing seizure frequency and improving depression rating scales over time with few associated side effects (Morris and Mueller, 1999; Elger et al., 2000; Harden et al., 2000; George et al., 2005; Nahas et al., 2005; Rush et al., 2005b; Kuba et al., 2009). The technology for VNS consists of surgically implanted electrodes coiled around the left vagus nerve. These electrodes are connected to a subcutaneously implanted stimulator that delivers specific intermittent electrical signals to the vagus nerve. The mechanisms underlying the efficacy of VNS remain unclear, but evidence suggests that it alters neuronal activity in forebrain afferents (Nemeroff et al., 2006). Indeed, imaging studies have demonstrated that VNS induces widespread changes in blood flow throughout the brain with significant reductions being observed in the hippocampus and amygdala within 18 h of VNS therapy (Henry et al., 1998, 2004; Kraus et al., 2007). Based on our hypothesis that hippocampal hyperactivity underlies the dopamine system dysregulation in schizophrenia, we posited that VNS would decrease hippocampal output and subsequently normalize aberrant dopamine system function in the MAM rodent model of schizophrenia.

\section{Materials and Methods}

All experiments were conducted in accordance with the United States Public Health Service Guide for the Care and Use of Laboratory Animals guidelines, and were approved by the Institutional Animal Care and Use Committee of the University of Texas Health and Science Center, San Antonio.

Animals. MAM treatments were performed as previously described (Moore et al., 2006; Lodge, 2013). Briefly, timed pregnant female Sprague-Dawley rats were administered MAM $(25 \mathrm{mg} / \mathrm{kg}$, i.p. $)$ on gestational day 17. Control rats receive an injection of saline $(1 \mathrm{mg} / \mathrm{kg}$, i.p.). Male pups were weaned on day 21 and housed in groups of two to three with littermates until adulthood ( $>$ postnatal day 60 ). All experiments were performed on multiple litters of MAM- and saline-treated rats.

Vagal nerve stimulator implantation. All survival surgeries were performed under general anesthesia and aseptic conditions as previously described (Furmaga et al., 2012; Carreno and Frazer, 2014). Briefly, MAM- and saline-treated rats $(\sim 400 \mathrm{~g})$ were anesthetized with a mixture of ketamine $(75 \mathrm{mg} / \mathrm{kg})$ and medetomidine $(0.5 \mathrm{mg} / \mathrm{kg})$, and coiled electrodes were implanted around the left vagus nerve. The electrodes were placed around the left cervical vagus nerve and carotid sinus, ventral to the carotid bifurcation. To direct action potential propagation preferentially toward the CNS, an anodal block was created at the distal lead by configuring the bipolar stimulating electrode with the cathode at the proximal lead and the anode at the distal lead. The electrodes were connected to a stimulator pack (Cyberonics) that was sutured in place in a subcutaneous pouch created on the back of the rat. Rats that received VNS stimulation were instrumented with an operational stimulator pack programmed by a hand-held computer. Control rats were implanted with a dummy stimulator pack identical in size and weight $(48 \times 33 \times 7.1$ $\mathrm{mm} ; 16 \mathrm{~g})$. After completion of the surgery, rats were given $1 \mathrm{mg} / \mathrm{kg}$ atipamezole. Seven days postsurgery the VNS stimulators were turned on for a minimum of $14 \mathrm{~d}$ before testing (Fig. 1). The stimulation paradigm consisted of one burst of $20 \mathrm{~Hz}, 250 \mu$ s pulse width, $250 \mu \mathrm{A}$ current for $30 \mathrm{~s}$ every $5 \mathrm{~min}$, which is the recommended initial stimulation parameters used clinically (Rush et al., 2005a,b).

Extracellular recordings. MAM- and saline-treated rats, previously implanted with VNS stimulator packs, were anesthetized with $8 \%$ chloral hydrate $(400 \mathrm{mg} / \mathrm{kg}$, i.p.). Supplemental anesthesia was given periodically as required to maintain suppression of the limb compression with-

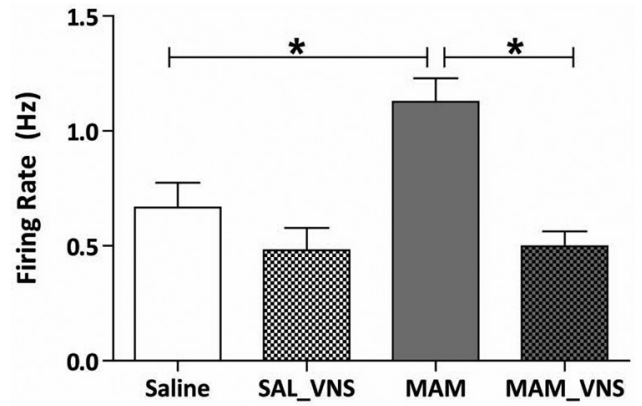

Figure 2. VNS normalizes enhanced firing rates of putative pyramidal neurons from the vHipp in MAM-treated rats receiving VNS ( $n=23-32$ cells per group; two-way ANOVA). Asterisk indicates significant difference from MAM-treated control rats.

drawal reflex. Rats were placed in a stereotaxic apparatus and core body temperature was maintained at $37^{\circ} \mathrm{C}$. Extracellular glass microelectrodes (impedance 6-10 M $\Omega$ ) were lowered into either the vHipp (A/P -5.0 ; $\mathrm{M} / \mathrm{L}+4.5 ; \mathrm{D} / \mathrm{V}-4.0$ to $-9.0 \mathrm{~mm}$ from bregma), or the ventral tegmental area (VTA: A/P $-5.3 ; \mathrm{M} / \mathrm{L}+0.6 ; \mathrm{D} / \mathrm{V}-6.5$ to $-9.0 \mathrm{~mm}$ from bregma). Putative pyramidal neurons were recorded in the vHipp, whereas dopamine neurons were identified in the VTA using standard electrophysiological criteria. It should be noted that apparent controversies around the identification of dopamine neurons in vivo have been recently addressed and it was determined that these cells can be reliably identified using standard electrophysiological approaches.

A subset of MAM-treated rats $(n=6)$ were used to examine the effects of acute VNS on VTA dopamine neuron activity. For these experiments, coiled electrodes were implanted around the left vagus nerve and connected to an external stimulator (Grass $88 \mathrm{X}$ ) via a stimulus isolation unit. These rats received stimulation (one burst of $20 \mathrm{~Hz}, 250 \mu$ s pulse width, $250 \mu \mathrm{A}$ current for $30 \mathrm{~s}$ every $5 \mathrm{~min}$ ) only for the duration of the electrophysiological recordings.

Amphetamine-induced locomotion. MAM- and saline-treated rats that had received chronic VNS (or sham) were placed in an open field arena (Med Associates) where spontaneous locomotor activity in the $x-y$ plane was determined for $45 \mathrm{~min}$ by beam breaks and recorded with Open Field Activity Software (Med Associates). Following the baseline period, all rats were then injected with D-amphetamine sulfate $(0.5 \mathrm{mg} / \mathrm{kg}$, i.p. $)$ and locomotor activity recorded for $45 \mathrm{~min}$. Rats then received an additional injection of D-amphetamine sulfate $(2.0 \mathrm{mg} / \mathrm{kg}$, i.p.) and locomotor activity recorded for an additional $45 \mathrm{~min}$.

Analysis. Electrophysiological analysis of putative pyramidal neuron and dopamine neuron activity was performed with commercially available computer software (LabChart version 7.1; ADInstruments) and analyzed using Prism software (GraphPad Software). Data are represented as the mean \pm SEM, with $n$ values representing the number of animals 

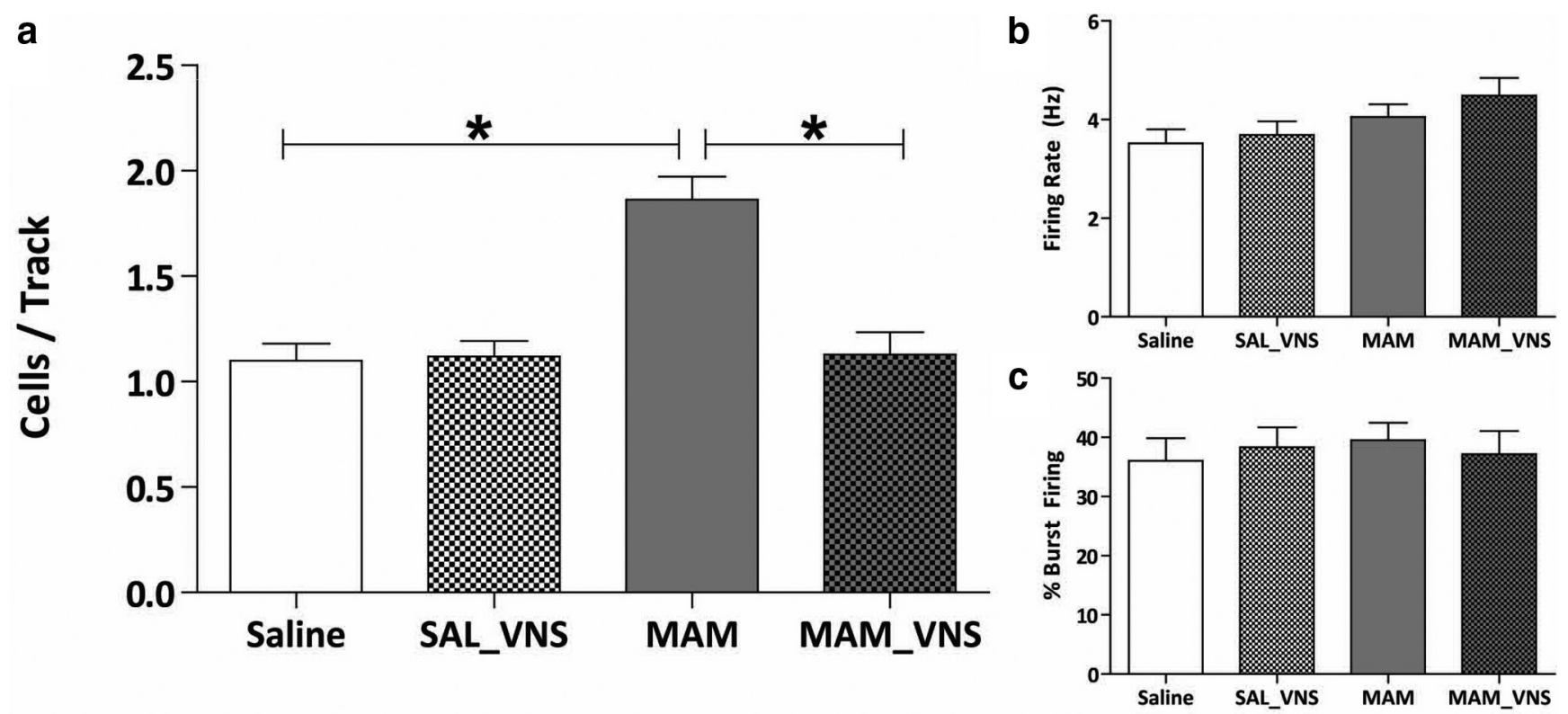

Figure 3. $\boldsymbol{a}$, VNS restores aberrant dopamine neuron population activity in the ventral tegmental area of MAM-treated rats ( $n=8$ rats per group; two-way ANOVA; $\boldsymbol{b}, \boldsymbol{c}$ ). VNS had no effect on the firing rate and burst firing respectively ( $n=55-93$ cells per group; two-way ANOVA). Asterisk indicates a significant difference from MAM-treated control rats.

per experimental group or number of neurons per group where indicated. Statistics were calculated using SigmaPlot (Systat Software).

Materials and methods. MAM was purchased from Midwest Research Institute. Ketamine was purchased from Butler Animal Health Supply and medetomidine from Pfizer. Chloral Hydrate and amphetamine were purchased from Sigma-Aldrich. VNS electrode leads and stimulator packs were obtained as a gift from Cyberonics. All other chemicals and reagents were of either analytical or laboratory grade and purchased from various suppliers.

\section{Results}

Increased vHipp firing rates are consistently observed in MAMtreated rats (Lodge and Grace, 2007; Perez and Lodge, 2013; Shah and Lodge, 2013). To examine whether VNS could decrease vHipp activity, putative pyramidal neuron activity was recorded throughout this region (Fig. 2). Consistent with previous observations (Lodge and Grace, 2007; Perez and Lodge, 2013; Perez et al., 2013), MAM-treated sham rats (VNS device implanted with no stimulation) display significantly higher firing rates $(n=30$ cells; $1.13 \mathrm{~Hz} \pm 0.10$ ) compared with saline-treated control rats $\left(n=29\right.$ cells; $0.67 \mathrm{~Hz} \pm 0.11$; two-way ANOVA; $\operatorname{strain} F_{(1,110)}=$ 6.39; treatment $F_{(1,110)}=18.53$; strain ${ }_{\mathrm{x} \text { Treatment }} F_{(1,110)}=5.48$; Holm-Sidak; $t=3.53 ; p<0.001)$. Saline-treated rats receiving VNS did not display a significant change in vHipp firing rate $(n=$ 23 cells; $0.48 \mathrm{~Hz} \pm 0.10$ ) compared with saline-treated controls (two-way ANOVA; Holm-Sidak; $t=1.33$; $p=0.19$ ). Interestingly, vHipp firing rates were normalized by VNS in MAMtreated rats $(n=32$ cells; $0.50 \mathrm{~Hz} \pm 0.06)$, as we observed a significant decrease in the firing frequency compared with MAM-treated sham rats (two-way ANOVA; Holm-Sidak; $t=$ 4.94; $p<0.001$ ). These data demonstrate that chronic VNS stimulation is sufficient to attenuate hippocampal activity in MAMtreated rats.

Additionally, downstream changes in dopamine neuron population activity in the VTA were observed in MAM-treated rats in response to VNS (Fig. 3). Again consistent with previous studies, saline-treated control rats $(n=8)$ displayed an average of $1.10 \pm$ 0.08 spontaneously active dopamine neurons per track (Lodge and Grace, 2007; Perez and Lodge, 2013; Perez, et al., 2013; Shah and Lodge, 2013). MAM-treated sham rats $(n=8)$ had a significantly higher number of spontaneously active dopamine neurons $(1.86 \pm 0.11)$ compared with saline-treated controls (two-way ANOVA; strain: $F_{(1,28)}=16.83$; treatment: $F_{(1,28)}=14.34$; strain $\times$ treatment: $F_{(1,28)}=16.06$; Holm-Sidak; $t=5.74 ; p<0.001)$, with no significant effect on firing rate or percentage burst firing, also consistent with previous studies (Lodge and Grace, 2007; Perez and Lodge, 2013; Perez et al., 2013). VNS was able to restore dopamine neuron population activity in MAM-treated rats $(n=8 ; 1.13 \pm 0.11$; Holm-Sidak; $t=5.51 ; p<0.001)$. A subset of MAM- and saline-treated rats received chronic VNS stimulation (minimum of $14 \mathrm{~d}$ ) followed by a withdrawal period of 7-10 d before electrophysiological testing to see whether the effects of VNS would persist without active stimulation (Fig. 4). Saline-treated rats recorded following VNS stimulation and withdrawal $(n=4)$ exhibited an average of $1.13 \pm$ 0.04 spontaneously active dopamine neurons per electrode tract. MAM-treated rats that were also examined following VNS and withdrawal $(n=3)$ exhibited a significantly higher dopamine neuron population activity ( $1.66 \pm 0.09 ; p=0.002$; Student's $t$ test; $t=-6.057$ with 5 degrees of freedom) without significantly altering average firing rate or percentage burst firing (Fig. 5). Similarly, MAM-treated rats that received acute VNS $(n=6)$ demonstrated a significantly higher dopamine neuron population activity compared with sham saline-treated rats ( $1.78 \pm 0.17$; $p=0.002$; Student's $t$ test; $t=-3.903$ with 12 degrees of freedom; Fig. 4). Together, these data provide evidence that the normalization of aberrant dopamine neuron population activity in MAM-treated rats requires chronic and sustained VNS stimulation.

To determine the physiological significance of the changes in neuronal activity, we examined the effects of chronic VNS on the locomotor response to amphetamine (Fig. 6; $n=7-8$ rats/ group). An augmented response to psychomotor stimulants is a consistent observation in both schizophrenia patients and rodent models, including MAM-treated rats. Although there may be concerns regarding the effects of a large stimulator implant on locomotor activity, we still observed an increased locomotor response to the $2.0 \mathrm{mg}$ dose of amphetamine in the MAM-treated 
A
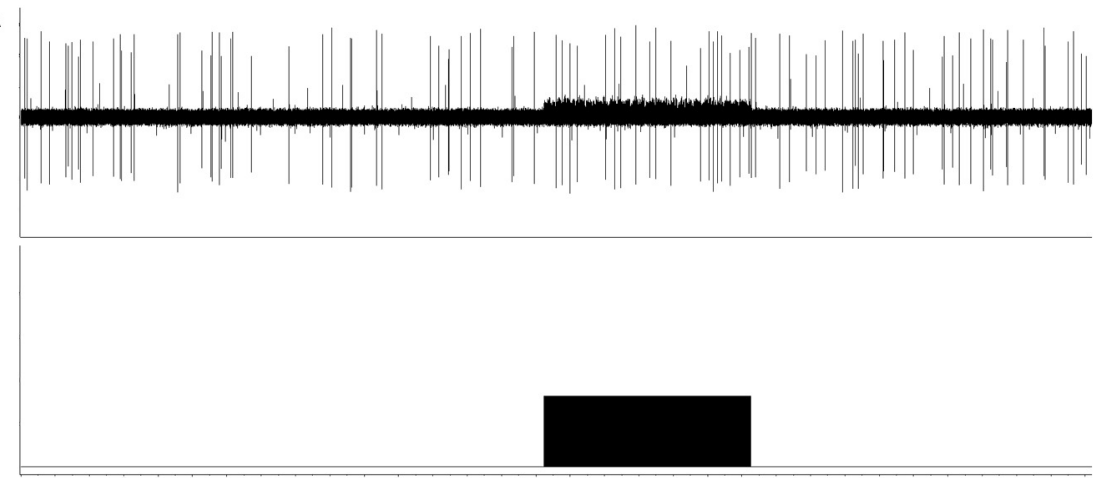

D
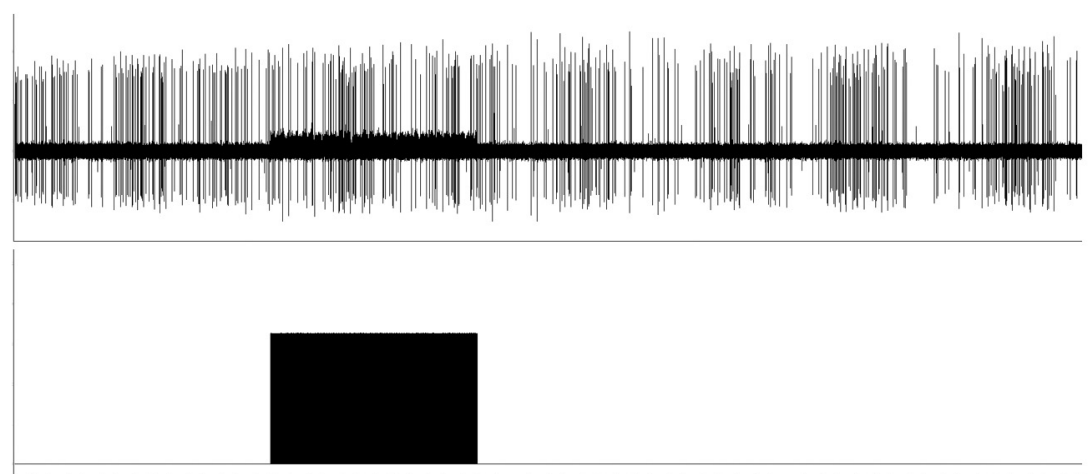

B

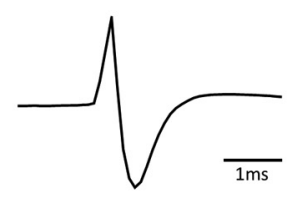

C
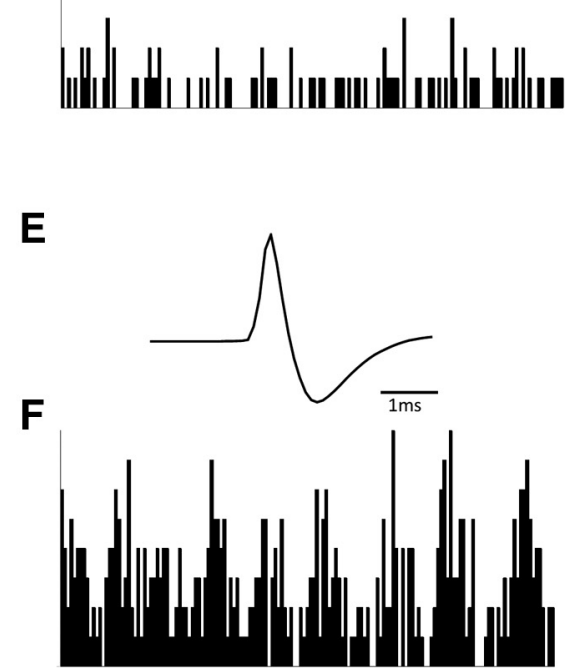

Figure 4. Representative traces demonstrating that acute VNS does not dramatically alter dopamine neuron activity. The period of VNS is depicted in the bottom of $\boldsymbol{A}$ and $\boldsymbol{D}$ alongside representative dopamine neuron waveforms $(\boldsymbol{B}, \boldsymbol{E})$ and firing rate histograms $(\boldsymbol{C}, \boldsymbol{F})$.
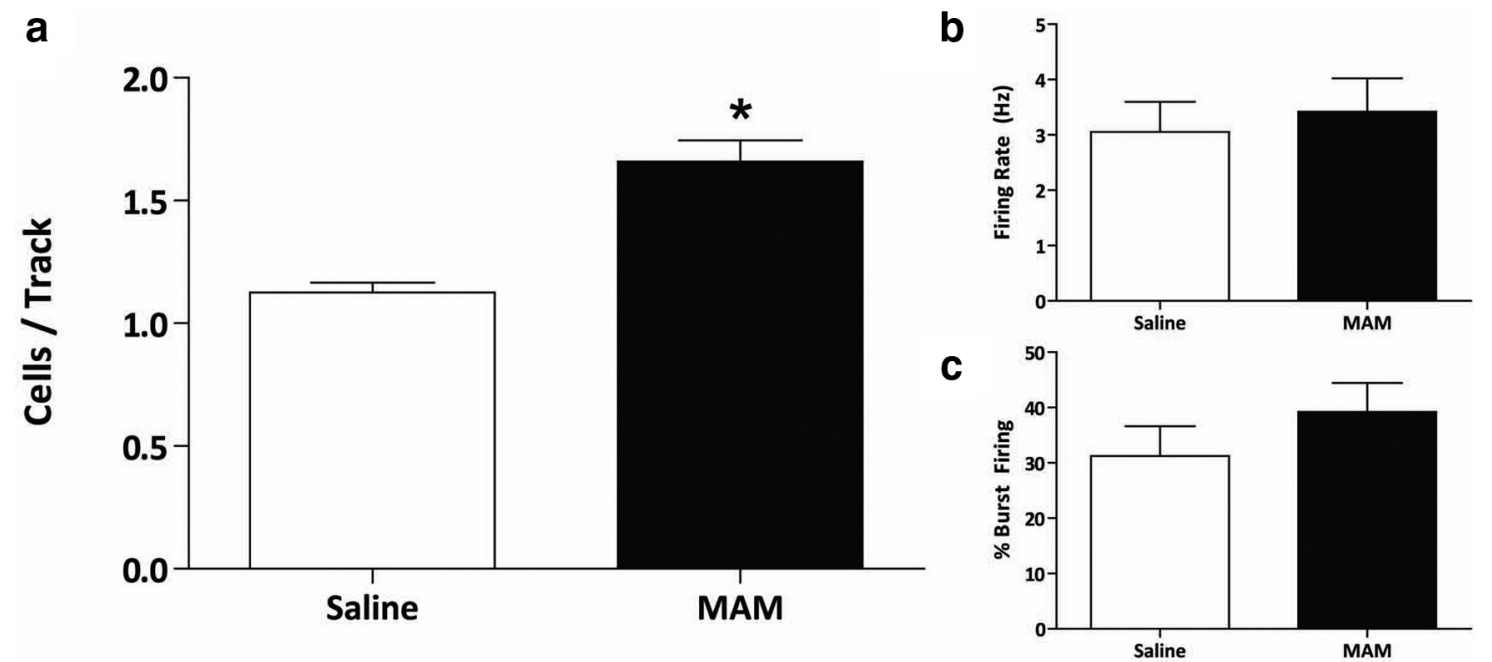

Figure 5. MAM-treated rats that were taken off of VNS for a period of $7-10 \mathrm{~d}$ did not display a significant decrease in dopamine neuron population activity ( $a, n=3-4$ rats per group; Student's $t$ test). $\boldsymbol{b}, \boldsymbol{c}$, No significant changes were observed in the firing frequency or burst firing of dopamine neurons ( $n=27-33$ cells per group; Student's $t$ test). Asterisk indicates a significant difference from saline-treated control rats.

rats (three-way ANOVA of Sham; strain: $F_{(1,324)}=20.879$; amphetamine dose: $F_{(2,324)}=264.834$; strain $\times$ dose: $F_{(2,324)}=$ 5.752; Holm-Sidak; $t=5.371 ; p<0.001)$. No such effect was observed in MAM-treated rats receiving VNS (three-way ANOVA of VNS; strain $\times$ dose: $\left.F_{(8,322)}=1.469 ; p>0.05\right)$, demonstrating that a beneficial effect of chronic VNS on a validated behavioral correlate of positive symptoms. It should be noted that one rat was removed from the analysis due to a dramatically reduced (by $\sim 90 \%$ ) locomotor response to amphetamine (total distance traveled in response to $0.5 \mathrm{mg}$ dose was $645 \mathrm{~cm}$ compared with a mean of $11,740 \pm 1672 \mathrm{~cm}$ ).

\section{Discussion}

The most important results from these studies are that chronic application of VNS, in MAM-treated rats, normalizes both hippocampal and VTA hyperactivity, as well as reversing the hyperresponsivity to the psychomotor stimulant, amphetamine. Such 
A

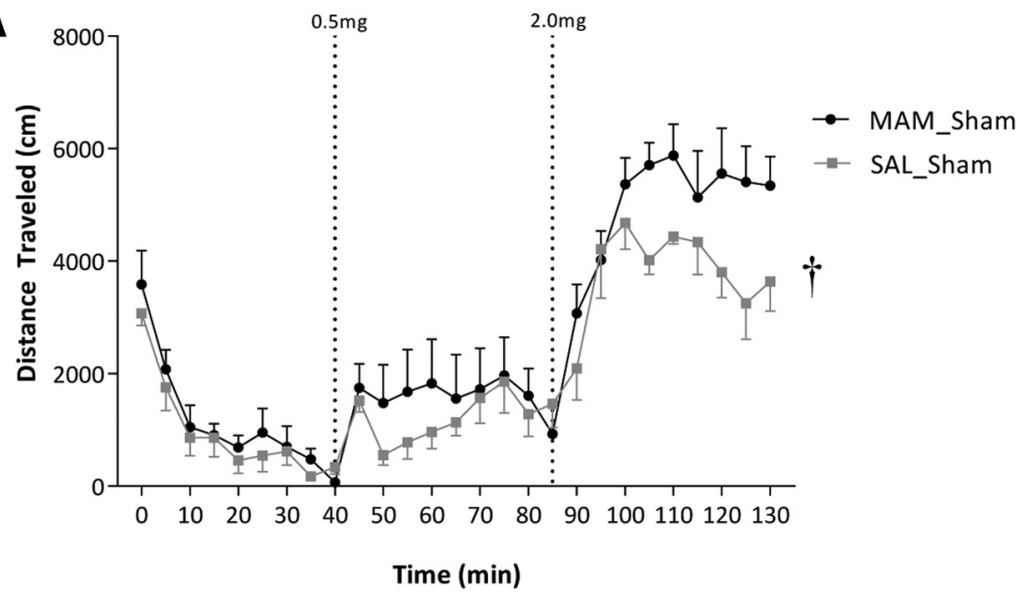

B

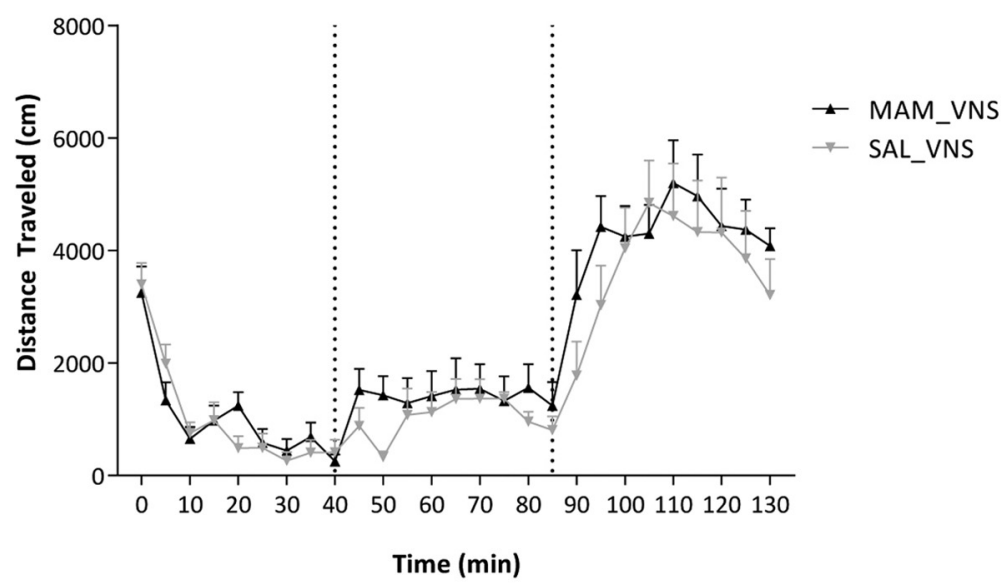

Figure 6. VNS reverses the behavioral hyper-responsivity to amphetamine in the MAM rodent model of schizophrenia. Specifically, MAM-treated rats display an enhanced locomotor response to amphetamine $(\boldsymbol{A})$ that is not present in rats receiving chronic VNS therapy ( $\boldsymbol{B} ; n=7-8$ rats per group; three-way ANOVA). Dagger indicates a significant difference from saline-treated control rats in response to the $2.0 \mathrm{mg} / \mathrm{kg}$ dose of amphetamine.

results are consistent with VNS having therapeutic potential in schizophrenia.

The dopamine hypothesis of schizophrenia (Laruelle and AbiDargham, 1999; Abi-Dargham, 2004) remains one of the most prominent theories of the disease, although it fails to provide a complete, all-encompassing explanation for the multitude of pathologies and symptoms seen in patients. This hypothesis does however provide evidence that aberrant mesolimbic dopamine signaling is likely responsible for the positive symptoms associated with the disease (Howes and Kapur, 2009). Because of the lack of pathology present within the dopamine system itself, scientists have looked elsewhere in the brain to develop a more integrated theory of schizophrenia (Harrison, 1999). Specifically, we believe aberrant mesolimbic dopamine signaling is a result of hyperactivity present within various subfields of the hippocampus (Lodge and Grace, 2011). Indeed, schizophrenia is a network disorder and there are observable brain pathologies present in areas other than the hippocampus (i.e., cortex; (Breier et al., 1992; Akbarian et al., 1995; Akil et al., 1999; Hashimoto et al., 2003); however, our preclinical evidence suggests that hippocampal hyperactivity drives mesolimbic dopamine system dysfunction. Furthermore, alterations in hippocampal circuitry are sufficient, in and of itself to induce aberrant dopamine signaling (Shah and Lodge, 2013). This is consistent with clinical data dem- onstrating that patients with schizophrenia exhibit elevated baseline activity within the hippocampus at rest (Heckers, 2001; Schobel et al., 2009a,b). Additionally, this is correlated with positive symptoms of the disease (Schobel et al., 2009b). This has led to the suggestion that targeting the vHipp may be a novel therapeutic approach for the treatment of schizophrenia. Indeed, we have successfully normalized aberrant dopamine system function and reversed associated behaviors with pharmacological (Gill et al., 2011), surgical (Perez et al., 2013), and cell-based (Perez and Lodge, 2013) manipulations of the hippocampus in a rodent model. Based on these observations, we tested the effectiveness of indirect manipulation of the hippocampus, by VNS, on dopamine system function and a behavioral correlate of positive symptoms.

VNS is an alternative therapy that has received FDA approval for the treatment of treatment-resistant epilepsy and treatment-resistant depression (Nemeroff et al., 2006). Pertinent to our hypothesis, VNS has been shown to reduce activity within the hippocampus in clinical depression (Henry et al., 1998, 2004; Kraus et al., 2007) and epilepsy. Thus, we propose that VNS will restore normal hippocampal function and normalize downstream dopamine neuron activity. To examine this hypothesis we used a gestation disruption model of schizophrenia, the MAM model. This model is integral to the study as MAM-treated rats consistently display neurophysiological, behavioral, and anatomical alterations which are commonly observed in patients with schizophrenia (Moore et al., 2006; Lodge and Grace, 2009). Consistent with our hypothesis, chronic application of VNS in MAM-treated rats normalized hippocampal hyperactivity and reversed aberrant dopamine system function. MAM-treated rats consistently demonstrate a significant increase in vHipp activity (Lodge and Grace, 2007; Perez and Lodge, 2012; Perez et al., 2013), which coincides with clinical data in humans, as patients with schizophrenia also display increased activity in hippocampal subfields (Schobel et al., 2009b).

Approximately $80 \%$ of the fibers that comprise the vagus nerve carry sensory information to the CNS (Nemeroff et al., 2006). Afferent fibers innervate the nucleus of the solitary tract (NTS), which in turn sends direct projections to many regions, including the locus ceruleus (LC) and dorsal raphe nucleus (Groves and Brown, 2005; Nemeroff et al., 2006). Although the exact mechanisms as to how VNS produces its therapeutic effects are not fully understood, it is thought to involve vagal afferents to the NTS, which in turn, modulate neuronal systems involved in mood regulation. Specifically, work by Manta et al. (2013) have demonstrated that VNS increases activity within serotonergic neurons of the raphe and norepinephrine (NE) neurons in the LC. Of relevance to the current study is the VNS-induced release of NE (from the LC), which projects to regions including the 
hippocampus (Roosevelt et al., 2006). Specifically, the rat hippocampus receives dense noradrenergic projections from the LC (Jones and Moore, 1977), which is important as NE has been shown to decrease pyramidal neuron activity in hippocampal subfields (Curet and de Montigny, 1988a,b). Indeed, chronic (14 d) VNS has been demonstrated to enhance tonic activation of $\alpha 2$-adrenoceptors onto pyramidal neurons within the hippocampus (Manta et al., 2013). Consistent with these findings, we now demonstrate that application of VNS normalizes the augmented activity of putative vHipp pyramidal neurons in MAMtreated rats.

Previous studies in MAM-treated rats have demonstrated that the hyperactivity in the vHipp drives a dopamine system dysfunction (Lodge and Grace, 2007) leading to an augmented response to psychomotor stimulants. Given that VNS was able to reverse aberrant vHipp activity, it seemed likely that VNS would also restore mesolimbic dopamine system function in MAM-treated rats. Indeed, VNS was able to significantly decrease VTA dopamine neuron population activity in MAM-treated rats to a level consistently displayed by control rats. This was correlated with a normalization of the aberrant behavioral response to amphetamine administration, consistently observed in the MAM model. Additionally, we found that the effects of VNS required chronic stimulation, are not present following acute stimulation and do not persist once the stimulator is turned off. It should be noted that conventional antipsychotic drugs decrease dopamine neuron activity, likely via depolarization blockade, resulting in a dramatically lower number of spontaneously active dopamine neurons compared with controls (Grace et al., 1997). This marked reduction (below control levels) is not observed with VNS and may therefore be better tolerated than conventional antipsychotics.

Together these results demonstrate that VNS is able to normalize aberrant vHipp activity, as well as, downstream alterations in VTA dopamine neuron activity and behavior in the MAM model of schizophrenia. Current pharmacological therapies for the treatment of schizophrenia are associated with adverse sideeffects including dyskinesias and metabolic side effects (Lieberman et al., 1988, 2005; Newcomer, 2005). Many patients discontinue treatment because of these side effects, whereas others discontinue because of a lack of efficacy (Lieberman et al., 2005). Such side effects are not seen in patients treated with VNS (Schachter, 2002). These data provide the first experimental evidence that VNS may be a possible nonpharmacological approach for the treatment of this debilitating disease.

\section{References}

Abi-Dargham A (2004) Do we still believe in the dopamine hypothesis? New data bring new evidence. Int J Neuropsychopharmacol 7:S1-S5. CrossRef

Akbarian S, Kim JJ, Potkin SG, Hagman JO, Tafazzoli A, Bunney WE Jr, Jones EG (1995) Gene expression for glutamic acid decarboxylase is reduced without loss of neurons in prefrontal cortex of schizophrenics. Archives of General Psychiatry 52:258-266. CrossRef Medline

Akil M, Pierri JN, Whitehead RE, Edgar CL, Mohila C, Sampson AR, Lewis DA (1999) Lamina-specific alterations in the dopamine innervation of the prefrontal cortex in schizophrenic subjects. Am J Psychiatry 156: 1580-1589. Medline

Bhugra D (2005) The global prevalence of schizophrenia. PLoS Med 2: e151. CrossRef Medline

Breier A, Buchanan RW, Elkashef A, Munson RC, Kirkpatrick B, Gellad F (1992) Brain morphology and schizophrenia: a magnetic resonance imaging study of limbic, prefrontal cortex, and caudate structures. Arch Gen Psychiatry 49:921-926. CrossRef Medline

Carreno FR, Frazer A (2014) Activation of signaling pathways downstream of the brain-derived neurotrophic factor receptor, TrkB, in the rat brain by vagal nerve stimulation and antidepressant drugs. Int J Neuropsychopharmacol 17:247-258. CrossRef Medline

Curet O, de Montigny C (1988a) Electrophysiological characterization of adrenoceptors in the rat dorsal hippocampus: I. Receptors mediating the effect of microiontophoretically applied norepinephrine. Brain Res 475: 35-46. CrossRef Medline

Curet O, de Montigny C (1988b) Electrophysiological characterization of adrenoceptors in the rat dorsal hippocampus: II. Receptors mediating the effect of synaptically released norepinephrine. Brain Res 475:47-57. CrossRef Medline

Elger G, Hoppe C, Falkai P, Rush AJ, Elger CE (2000) Vagus nerve stimulation is associated with mood improvements in epilepsy patients. Epilepsy Res 42: 203-210. CrossRef Medline

Furmaga H, Carreno FR, Frazer A (2012) Vagal nerve stimulation rapidly activates brain-derived neurotrophic factor receptor TrkB in rat brain. PLoS One 7:e34844. CrossRef Medline

George MS, Rush AJ, Marangell LB, Sackeim HA, Brannan SK, Davis SM, Howland R, Kling MA, Moreno F, Rittberg B, Dunner D, Schwartz T, Carpenter L, Burke M, Ninan P, Goodnick P (2005) A one-year comparison of vagus nerve stimulation with treatment as usual for treatmentresistant depression. Biol Psychiatry 58:364-373. CrossRef Medline

Gill KM, Lodge DJ, Cook JM, Aras S, Grace AA (2011) A novel alpha5GABA(A)R-positive allosteric modulator reverses hyperactivation of the dopamine system in the MAM model of schizophrenia. Neuropsychopharmacology 36:1903-1911. CrossRef Medline

Grace AA, Bunney BS, Moore H, Todd CL (1997) Dopamine-cell depolarization block as a model for the therapeutic actions of antipsychotic drugs. Trends Neurosci 20:31-37. CrossRef Medline

Groves DA, Brown VJ (2005) Vagal nerve stimulation: a review of its applications and potential mechanisms that mediate its clinical effects. Neurosci Biobehav Rev 29:493-500. CrossRef Medline

Harden CL, Pulver MC, Ravdin LD, Nikolov B, Halper JP, Labar DR (2000) A pilot study of mood in epilepsy patients treated with vagus nerve stimulation. Epilepsy Behav 1:93-99. CrossRef Medline

Harrison PJ (1999) The neuropathology of schizophrenia: a critical review of the data and their interpretation. Brain 122:593-624. CrossRef Medline

Hashimoto T, Volk DW, Eggan SM, Mirnics K, Pierri JN, Sun Z, Sampson AR, Lewis DA (2003) Gene expression deficits in a subclass of GABA neurons in the prefrontal cortex of subjects with schizophrenia. J Neurosci 23:6315-6326. Medline

Heckers S (2001) Neuroimaging studies of the hippocampus in schizophrenia. Hippocampus 11:520-528. CrossRef Medline

Heckers S, Rauch SL, Goff D, Savage CR, Schacter DL, Fischman AJ, Alpert NM (1998) Impaired recruitment of the hippocampus during conscious recollection in schizophrenia. Nat Neurosci 1:318-323. CrossRef Medline

Henry TR, Bakay RA, Votaw JR, Pennell PB, Epstein CM, Faber TL, Grafton ST, Hoffman JM (1998) Brain blood flow alterations induced by therapeutic vagus nerve stimulation in partial epilepsy: I. Acute effects at high and low levels of stimulation. Epilepsia 39:983-990. CrossRef Medline

Henry TR, Bakay RA, Pennell PB, Epstein CM, Votaw JR (2004) Brain blood-flow alterations induced by therapeutic vagus nerve stimulation in partial epilepsy: II. prolonged effects at high and low levels of stimulation. Epilepsia 45:1064-1070. CrossRef Medline

Howes OD, Kapur S (2009) The dopamine hypothesis of schizophrenia: version III-the final common pathway. Schizophr Bull 35: 549-562. CrossRef Medline

Jones BE, Moore RY (1977) Ascending projections of the locus coeruleus in the rat: II. Autoradiographic study. Brain Res 127:25-53. Medline

Kraus T, Hösl K, Kiess O, Schanze A, Kornhuber J, Forster C (2007) BOLD fMRI deactivation of limbic and temporal brain structures and mood enhancing effect by transcutaneous vagus nerve stimulation. J Neural Transm 114:1485-1493. CrossRef Medline

Kuba R, Brázdil M, Kalina M, Procházka T, Hovorka J, Nezádal T, Hadac J, Brozová K, Sebronová V, Komárek V, Marusic P, Oslejsková H, Zárubová J, Rektor I (2009) Vagus nerve stimulation: longitudinal follow-up of patients treated for 5 years. Seizure 18:269-274. CrossRef Medline

Laruelle M, Abi-Dargham A (1999) Dopamine as the wind of the psychotic fire: new evidence from brain imaging studies. J Psychopharmacol 13: 358-371. CrossRef Medline

Lieberman, Lesser M, Johns C, Pollack S, Saltz B, Kane J (1988) Pharmaco- 
logic studies of tardive dyskinesia. J Clin Psychopharmacol 8:57S-63S. CrossRef Medline

Lieberman JA, Stroup TS, McEvoy JP, Swartz MS, Rosenheck RA, Perkins DO, Keefe RS, Davis SM, Davis CE, Lebowitz BD, Severe J, Hsiao JK (2005) Effectiveness of antipsychotic drugs in patients with chronic schizophrenia. N Engl J Med 353:1209-1223. CrossRef Medline

Lodge DJ (2013) The MAM rodent model of schizophrenia. Curr Protoc Neurosci 9:43. CrossRef Medline

Lodge DJ, Grace AA (2007) Aberrant hippocampal activity underlies the dopamine dysregulation in an animal model of schizophrenia. J Neurosci 27:11424-11430. CrossRef Medline

Lodge DJ, Grace AA (2009) Gestational methylazoxymethanol acetate administration: a developmental disruption model of schizophrenia. Behav Brain Res 204:306-312. CrossRef Medline

Lodge DJ, Grace AA (2011) Hippocampal dysregulation of dopamine system function and the pathophysiology of schizophrenia. Trends Pharmacol Sci 32:507-513. CrossRef Medline

Manta S, El Mansari M, Debonnel G, Blier P (2013) Electrophysiological and neurochemical effects of long-term vagus nerve stimulation on the rat monoaminergic systems. Int J Neuropsychopharmacol 16:459-470. CrossRef Medline

Medoff DR, Holcomb HH, Lahti AC, Tamminga CA (2001) Probing the human hippocampus using rCBF: contrasts in schizophrenia. Hippocampus 11:543-550. CrossRef Medline

Moore H, Jentsch JD, Ghajarnia M, Geyer MA, Grace AA (2006) A neurobehavioral systems analysis of adult rats exposed to methylazoxymethanol acetate on E17: implications for the neuropathology of schizophrenia. Biol Psychiatry 60:253-264. CrossRef Medline

Morris GL $3^{\text {rd }}$, Mueller WM (1999) Long-term treatment with vagus nerve stimulation in patients with refractory epilepsy: The Vagus Nerve Stimulation Study Group E01-E05. Neurology 53:1731-1735. CrossRef Medline

Nahas Z, Marangell LB, Husain MM, Rush AJ, Sackeim HA, Lisanby SH, Martinez JM, George MS (2005) Two-year outcome of vagus nerve stimulation (VNS) for treatment of major depressive episodes. J Clin Psychiatry 66:1097-1104. CrossRef Medline

Nemeroff CB, Mayberg HS, Krahl SE, McNamara J, Frazer A, Henry TR, George MS, Charney DS, Brannan SK (2006) VNS therapy in treatment-resistant depression: clinical evidence and putative neurobiological mechanisms. Neuropsychopharmacology 31:1345-1355. CrossRef Medline

Newcomer JW (2005) Second-generation (atypical) antipsychotics and metabolic effects: a comprehensive literature review. CNS Drugs 19:1-93. CrossRef Medline
Perez SM, Lodge DJ (2012) Aberrant dopamine D2-like receptor function in a rodent model of schizophrenia. J Pharmacol Exp Ther 343:288-295. CrossRef Medline

Perez SM, Lodge DJ (2013) Hippocampal interneuron transplants reverse aberrant dopamine system function and behavior in a rodent model of schizophrenia. Mol Psychiatry 18:1193-1198. CrossRef Medline

Perez SM, Shah A, Asher A, Lodge DJ (2013) Hippocampal deep brain stimulation reverses physiological and behavioural deficits in a rodent model of schizophrenia. Int J Neuropsychopharmacol 16:1331-1339. CrossRef Medline

Roosevelt RW, Smith DC, Clough RW, Jensen RA, Browning RA (2006) Increased extracellular concentrations of norepinephrine in cortex and hippocampus following vagus nerve stimulation in the rat. Brain Res 1119:124-132. CrossRef Medline

Rush AJ, Marangell LB, Sackeim HA, George MS, Brannan SK, Davis SM, Howland R, Kling MA, Rittberg BR, Burke WJ, Rapaport MH, Zajecka J, Nierenberg AA, Husain MM, Ginsberg D, Cooke RG (2005a) Vagus nerve stimulation for treatment-resistant depression: a randomized, controlled acute phase trial. Biol Psychiatry 58:347-354. CrossRef Medline

Rush AJ, Sackeim HA, Marangell LB, George MS, Brannan SK, Davis SM, Lavori P, Howland R, Kling MA, Rittberg B, Carpenter L, Ninan P, Moreno F, Schwartz T, Conway C, Burke M, Barry JJ (2005b) Effects of 12 months of vagus nerve stimulation in treatment-resistant depression: a naturalistic study. Biol Psychiatry 58:355-363. CrossRef Medline

Saha S, Chant D, Welham J, McGrath J (2005) A systematic review of the prevalence of schizophrenia. PLoS Med 2:e141. CrossRef Medline

Schachter SC (2002) Vagus nerve stimulation therapy summary: five years after FDA approval. Neurology 59: S15-20. CrossRef Medline

Schobel SA, Kelly MA, Corcoran CM, Van Heertum K, Seckinger R, Goetz R, Harkavy-Friedman J, Malaspina Da (2009) Anterior hippocampal and orbitofrontal cortical structural brain abnormalities in association with cognitive deficits in schizophrenia. Schizophr Res 114: 110-118. CrossRef Medline

Schobel SA, Lewandowski NM, Corcoran CM, Moore H, Brown T, Malaspina D, Small SA (2009) Differential targeting of the CA1 subfield of the hippocampal formation by schizophrenia and related psychotic disorders. Arch Gen Psychiatry 66:938-946. CrossRef Medline

Shah A, Lodge DJ (2013) A loss of hippocampal perineuronal nets produces deficits in dopamine system function: relevance to the positive symptoms of schizophrenia. Transl Psychiatry 3:e215. CrossRef Medline

Tamminga CA, Stan AD, Wagner AD (2010) The hippocampal formation in schizophrenia. Am J Psychiatry 167:1178-1193. CrossRef Medline 